\title{
Grandiose narcissism and performance in organizations: mediating role of subjective wellbeing
}

\author{
Kiran Sakkar Sudha ${ }^{1}$ (D) M. Ghazi Shahnawaz ${ }^{1}$
}

Received: 12 July 2020 / Accepted: 18 November 2020 / Published online: 3 December 2020

(c) The Author(s) 2020

\begin{abstract}
Narcissism is imbued with emotional dynamism and there is a strong need to assess the linkages with outcomes by analyzing their fusion. The present study examined the relationship between grandiose narcissism and performance through analyzing the mediating role of subjective wellbeing (positive affect, negative affect and life satisfaction). The wholesome assessment of performance was done by considering task performance, team-work and cognitive motivational effectiveness among 293 senior-level Indian employees of a big public sector organization. Data were analyzed by using SPSS 22 and Smart PLS 2.0. The correlation results showed that grandiose narcissism was negatively related to performance, life satisfaction and positively related to negative affect. The indirect pathways (through mediation analyses) revealed that negative affect and life satisfaction mediated the relationship between grandiose narcissism and performance. The study effectively contributes to the narcissism and performance literature by presenting clearer pathways of grandiose narcissism (through self-regulated emotions and subjective wellbeing). Practical implications werealso highlighted beside the theoretical concerns.
\end{abstract}

Keywords Grandiose narcissism $\cdot$ Subjective wellbeing $\cdot$ Performance $\cdot$ Mediation analysis

\section{Introduction}

Narcissistic leaders have intrigued the researchers as they usually hog the limelight. It appears that individuals high on narcissism surface easily (Rosenthal and Pittinsky 2006) as they often fit into the prototypical leaders (because of their grandiosity). Originally narcissism was considered as negative (Lubit 2002) but lately, narcissism construct has been broadened and is considered as both positive and negative (Czarna and Nevicka 2019). Narcissistic leaders experience high positive affect as well as wellbeing (GornikDurose 2020) and their behavior is also regulated by state and affect/emotions (Chen et al. 2019) but this contingency is still evolving. There is a fusion between narcissism and emotions which is manifested in narcissist's thriving behavior and performance (Uji et al. 2014). On the other hand, narcissists also report hypersensitivity and anger, lack of

M. Ghazi Shahnawaz

mgshahnawaz@gmail.com; mshahnawaz@jmi.ac.in

Kiran Sakkar Sudha

kiran_ssudha@yahoo.com

1 Jamia Millia Islamia, New Delhi, India empathy, irrationality and inflexibility (APA 2000) etc. There is also some evidence to show that if narcissistic leaders can control some of their emotions, such as arrogance with humility, they can become a better performer, be more effective, and can experience satisfaction, wellbeing etc. (Owens et al. 2015). Moreover, the relationship between narcissism and performance has been fairly inconsistent (Wallace and Baumister 2002) and is likely to be moderated by many contextual factors (Nevicka et al. 2011; Imran and Shahnawaz 2020; Sakkar Sudha and Shahnawaz 2020). The present research is a modest attempt to clear some of these ambiguities by exploring the relationship of narcissistic leadership with performance through the mediation of subjective well-being, which has not been explored so far to the best of our knowledge.

\section{Narcissism}

Earlier narcissism used to be considered a unidimensional construct (Ames et al. 2006), but of late, grandiose and vulnerable narcissism have emerged as two sides of the narcissism construct (Pincus and Lukowitsky 2010). Grandiose narcissist is characterized as having arrogance, 
inflated self-esteem, entitlement, extraversion and strong admiration needs whereas vulnerable narcissist is propped by fragile affective states, hostility, low self-esteem and inversely related most characteristics of grandiosity (Krizan and Herlache 2018; Miller et al. 2012). Researches in the past have emphasized working on grandiose and vulnerable narcissism separately for more pronounced results (Aradhye and Vonk 2014; Miller et al. 2013). The concurrent and the controversial debate in narcissism literature is over constituents of normal, grandiose and vulnerable narcissism. There is no conclusive agreement to date over adaptive and maladaptive consequences of all these abovelisted categories (Miller et al. 2017). The probable reasons we attribute to this inconsistency is emotion and cognitive biases among narcissists (any category). Hence, with conflation over what constitutes the features of grandiose narcissism, vulnerable and normal narcissism is due to no clear thresholds (Malkin et al. 2012; Pincus and Lukowitsky 2010), grandiose narcissism is typically seen as adaptive and referred to as normal narcissism (Miller et al. 2014a, b). The Narcissism personality inventory (Raskin and Terry 1988) and NPI -16 (Ames et al. 2006) is considered a primary measure of grandiose narcissism (Krusemark et al. 2018) with remarkable psychometric properties (Gentile et al. 2013) which has also been used in the current study. In the present research we have focused on grandiose narcissism only as the prime idea of the research is to explore the clear pathways between narcissism and performance.

Since narcissism under any variation can influence organizational functioning in both positive and negative ways. The grandiose narcissism is characterized by positive intrapersonal functioning, such as emotion regulation, high self-esteem etc. and negative interpersonal functioning (usually long term) (Foster and Twenge 2011). The interpersonal strategies are used to regulate emotions by both vulnerable and grandiose narcissism (Morf and Rhodewalt 2001) and can have varying intrapersonal and interpersonal effects. Extant literature on narcissistic leaders found both productive and counterproductive outcomes (Czarna and Nevicka 2019; Furtner et al. 2017). The growing literature on narcissism has indicated the ambivalent nature of the construct but generally, narcissist has an affective and cognitive preoccupation with oneself (Westen 1990) and most of the study focused on vagaries of narcissism as an idiosyncratic trait (Chen et al. 2019; Sedikides and Campbell 2017). Narcissism also has a state-dependent feature (Chen et al. 2019), i.e. its functioning may vary depending on the context (Nevicka et al. 2011; Rosenthal and Pittinsky2006) and affective states (Cheng et al. 2013) leading to positive or negative outcomes. There are only a few studies on the interdependence of narcissism on wellbeing (Campbell and Campbell 2009; Morf and Rhodewalt
2001) and there are none to the best of our knowledge as to how the relationship of narcissism and wellbeing would affect organizational performance. Thus, the present study is a modest attempt to examine how wellbeing (Subjective Wellbeing) mediates the relationship of narcissistic leaders and organizational performance.

\section{Subjective wellbeing (SWB)}

Previous studies have found strong relationships between narcissism personality trait and SWB (Pilch 2020). SWB is operationalized as a combination of higher life satisfaction, high levels of positive affect and low negative affect (Deci and Ryan 2008). These two components of SWB: balancing of positive and negative affective states (moods and emotions) and cognitive evaluation of life depicts SWB index (Diener 2000) are the core constituents of SWB. The manifestation of emotions prepare individuals to respond optimally when situations are risky (negative affect) or opportunistic (positive affect) (Nesse 1990). Life satisfaction is cognitive evaluation of one's quality of life based on a certain preset criterion (Pavot and Diener 2003). There is evidence that affective states are emotional expressions which are short term and strongly determined by personality (Isen and Baron 1991). Therefore, SWB would also be influenced by narcissism (Campbell and Campbell 2009). However, the combined effect of both narcissism and wellbeing can have both negative (Grijalva et al. 2015) and positive consequences (Rose 2002).

Grandiose narcissists generally experience high wellbeing and positive affect unlike vulnerable narcissism (Sandage et al. 2016), i.e., primarily because they overestimate their abilities as well as emotional skills (Lobbestael et al. 2016). The reasons for their affective overestimation is attributed to momentary reactions to unfulfilled narcissistic needs of admiration and recognition (Roche et al. 2013). Another reason for greater wellbeing is that narcissism is closely related to self-esteem (Gornik-Durose 2020; Sedikides et al. 2004). The higher self-esteem is traditionally viewed as narcissist's "false mask" and underneath is a vague notion of "self" in all domains of life (Morf and Rhodewalt 2001). Narcissists try to replenish the ambiguity around them by optimally utilizing negative and positive emotions as a defense and perhaps wellbeing is a possible pathway through which grandiose narcissists deliver organizational performance, surprisingly this pathway has not been explored so far in the literature to the best of our knowledge. Thus, the present research is an attempt to explore this neglected pathway which would provide a much needed clarity on the grandiose narcissism and performance linkages. 


\section{Performance}

The relationship between narcissism and performance has been inconsistent (Wallace and Baumister 2002). Some research shows that narcissistic leaders positively affect performance because of their influence, charisma and ability to deal with complex situations (Galvin et al. 2010; Chatterjee and Hambrick 2007). On the contrary, narcissistic leaders also perform poorly (Braun 2017; Rosenthal 2010) due to poor decision making, incomprehensible goals and haphazard ways of functioning and may also falter over time (Rosenthal and Pittinksky 2006). The varying effect on performance is because of myriad reasons such as cognitive, affective and motivation competencies, inter group relations, type of tasks, ability to handle the tasks (Bashaer et al. 2016; Judge and Zapata 2015) and different indicators of performance used by different researchers (e.g., Ames and Kammrath 2004; Meier and Semmer 2013). However, in the context of the present research we have especially focused on cognitive and affective factors (SWB) as well as on the complexity of performance measures only. Narcissism and SWB have already been discussed in the earlier section of the paper. Organizational performance is a multifaceted construct and it comprises of in-role performance, contextual performance, and attitudinal dimensions of performance (Harrison et al. 2006). In the current paper, we have used the multidimensional framework of measuring performance by Greene Shortridge (2008). Hence, we evaluated three dimensions, namely, task performance, co-worker support and teamwork and cognitive/motivational effectiveness. The task performance taps factors like task proficiency, communication proficiency, ability to manage leadership position and management/administration activities (Campbell et al. 1996; Motowidlo and Schmit 1999). The ability to work coherently with the team reflects on the interpersonal ability of an individual as organizations have team-based goals and it is crucial to performance on how effectively coworkers identify with the shared tasks and support each other to perform (Scarnati 2001; Harris and Harris 1996). Cognitive motivational effectiveness (CME) is basically a skill set required to sustain and enhance task and team performances (Kanfer 1992). CME is a contingent aspect of performing which aids in understanding how well an individual manages cognition, motivations and emotions at work (Tett and Burnett 2003; McCrae 2000). As mentioned above, some of the inconsistency in the narcissism-performance measure is because of using a different measure of performance, the present research also aims to provide some clarity on this by measuring performance in a multifaceted manner.

\section{Current study}

Recent literature on narcissism has suggested that there is a need to assess self-regulatory processes such as wellbeing which might affect behaviors of narcissistic leaders in a social and organizational setting (Grapsas et al. 2020). Extant research has been done in the area of narcissism and wellbeing (Wirtz and Riggotti 2020); wellbeing and performance (Bryson et al. 2017; Oswald et al. 2015; Imran and Shahnawaz 2020; Sakkar Sudha and Shahnawaz 2020) and narcissism and performance (Grijalva et al. 2015; Imran and Shahnawaz 2020; Sakkar Sudha and Shahnawaz 2020). It would be pertinent to mention that grandiose narcissists generally experience high wellbeing and positive affect (Sandage et al. 2016). The reasons attributed to grandiose narcissist's positive valence mood is their overestimation of cognitive as well as emotional abilities (Lobbestael et al. 2016), higher self-esteem (GornikDurose 2020; Sedikides et al. 2004) and magnified self-image (Campbell et al. 2000). Therefore, we assumed that grandiose narcissist's tendency to experience positive cognition and emotions would prod them to perform well in the organizational context. Thus, the aim of the current paper is to empirically test the mediating pathways of subjective wellbeing (affective states and life satisfaction) between grandiose narcissism and performance. This may also help in resolving the inconsistency found in the narcissism - performance literature. The following hypotheses have been formed in the light of above:

H1: There would be a relationship between grandiose narcissism, subjective wellbeing (affective states and life satisfaction) and performance

H2: Positive affect would mediate the relationship between grandiose narcissism and performance (task performance, teamwork/co-worker support and cognitive motivational effectiveness)

H3: Negative affect would mediate the relationship between grandiose narcissism and performance (task performance, teamwork/co-worker support and cognitive motivational effectiveness)

H4: Satisfaction with life would mediate the relationship between grandiose narcissism and performance (task performance, teamwork/co-worker support and cognitive motivational effectiveness)

\section{Sample}

The data was collected through purposive and snowball techniques from 293 senior level managers from power generation sector (Public sector undertakings, India). They have the experience of ten to sixteen years. Out of 293 employees, 148 were males and 145 were females. The age range was from 34 to 46 years and the mean age was 37.3 years. 


\section{Measures}

Narcissism was measured using Narcissistic Personality Inventory (NPI 16) (Ames et al. 2006). It is a self-report inventory with 16 sets of statements indicating closely resembling behavior of narcissists (rated as " 1 ") and nonnarcissists (rated as " 0 "). It is a unidimensional scale and higher score indicates high narcissism. The Cronbach alpha on the current sample was 0.62 .

The subjective wellbeing was assessed using two scales namely Satisfaction with Life Scale (Diener et al. 1985) and Positive and Negative Affect Schedule (PANAS-X) (Watson et al. (1988). The Satisfaction with Life Scale (SWLS) measures global cognitive evaluations or judgments of satisfaction with one's own life on a seven-point Likert scale ranging from "strongly agree" to "strongly disagree". It is a 5 item scale with Cronbach Alpha as 0.75 on the current sample. (PANAS-X) comprises of 20 adjectives ( 10 for positive and 10 for negative affect). The participants indicate the extent to which they experience these emotions in general on a five point Likert scale ranging from 1 as "not at all" to 5 as "extremely". The Cronbach Alpha for the PA and NA scales were 0.89 and 0.77 respectively.

Performance was evaluated using 12 item scale by Greene-Shortridge (2008). It is a five point Likert scale ranging from 1 (Not at all) to 5 (Better than the best). The performance scale has three dimensions namely task performance (four items), teamwork/Co-worker Support (three items) and cognitive-motivational effectiveness, CME (five items) which are to be scored separately. The Cronbach's Alpha for performance dimensions are: (0.93), (0.90) and CME (0 0.91) respectively.

\section{Results and interpretation}

The results were analyzed using SPSS version 22 and SmartPLS 2. The study explored direct and indirect relationships among narcissism, subjective wellbeing and performance. Grandiose Narcissism (hereafter, narcissism) and performance was considered as exogenous and endogenous variables respectively and subjective wellbeing (Positive affect, negative affect and satisfaction with life) as mediating variable in the path analysis.

As can be inferred from Table 1, the mean score of narcissism is 7.39 , showing a moderate level of narcissism. The mean value of positive affect, negative affect and satisfaction with life are 29.56 (moderate), 34.61 (moderate) and 24.29 (moderate) respectively. The mean scores on performance dimensions were high on three dimensions namely task performance, teamwork and cognitive-motivational effectiveness dimensions are 16.14, 10.00 and 19.71 respectively.

The results of correlation analysis (Table 1) shows that narcissism is significantly related to positive affect $(r=0.30$, $\mathrm{p}<0.01)$, inversely related to negative affect $(\mathrm{r}=-0.14$, $\mathrm{p}<0.05$ ) and negatively related to satisfaction with life $(r=-0.16, p<0.01)$. Narcissism personality trait is negatively and significantly related to all three dimensions of performance $(p<0.01)$. The relationship of subjective wellbeing dimensions with performance shows that positive affect is significantly related to task performance teamwork and CME ( $\mathrm{p}<0.01)$; negative affect is negatively and significantly related to task performance and teamwork $(\mathrm{P}<0.01)$ and positively with CME $(\mathrm{p}<0.01)$. Satisfaction with life is significantly related with task performance, teamwork and cognitive motivation effectiveness $(p<0.01)$. Additionally, all performance dimensions were highly significant with each other $(\mathrm{p}<0.01)$. Thus, Hypothesis 1 is partially accepted.

The mediation relationship of subjective wellbeing with narcissism and performance was computed using SmartPLS2 software. The path coefficient was transformed into $t$ statistic using bootstrapping (Hair et al. 2017). The
Table 1 Showing descriptive statistics of all the variables used in the study

\begin{tabular}{lrllllllll}
\hline Variables & Mean & SD & 1 & 2 & 3 & 4 & 5 & 6 & 7 \\
\hline 1. Narcissism & 7.39 & 3.61 & 1 & & & & & & \\
2. PA & 29.56 & 9.57 & $0.30^{* *}$ & 1 & & & & & \\
3. NA & 34.61 & 8.16 & $-0.14^{*}$ & $-0.18^{* *}$ & 1 & & & & \\
4. SWL & 24.29 & 6.26 & $-0.16^{* *}$ & -0.07 & $0.42^{* *}$ & 1 & & & \\
5. Task performance & 16.14 & 3.93 & $-0.24^{* *}$ & $0.15^{* *}$ & $-0.38^{* *}$ & $0.37^{* *}$ & 1 & & \\
6. Teamwork & 10.00 & 3.58 & $-0.32^{* *}$ & $0.19^{* *}$ & $-0.26^{* *}$ & $0.23^{* *}$ & $0.40^{* *}$ & 1 & \\
7. Cognitive Motiva- \\
\begin{tabular}{l} 
tional effectiveness \\
\hline
\end{tabular} & 19.71 & 3.94 & $-0.13^{*}$ & -0.02 & $0.29^{* *}$ & $0.26^{* *}$ & $0.46^{* *}$ & $0.49^{* *}$ & 1 \\
\hline
\end{tabular}

Mean, SD and correlation of study variables, ${ }^{*} p<<0.01, * p<0.05, N=293$ 
Fig. 1 Positive affect (PA) as a mediator of narcissism (Nar.) and performance (task performance, teamwork and cognitive motivational effectiveness, CME)

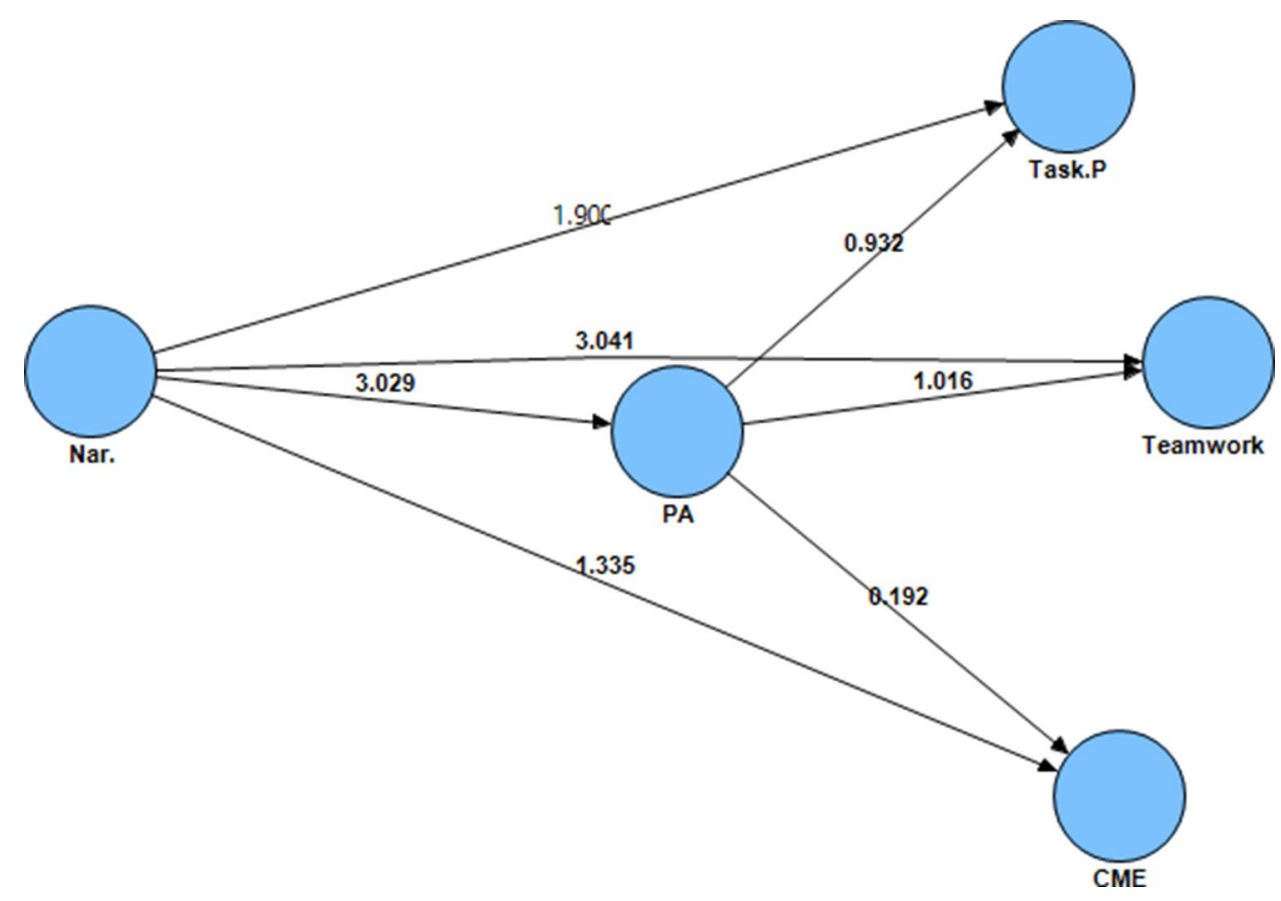

Fig. 2 Negative affect (NA) as mediator of narcissism (Nar.) and performance (task performance, teamwork and cognitive motivational effectiveness, CME)

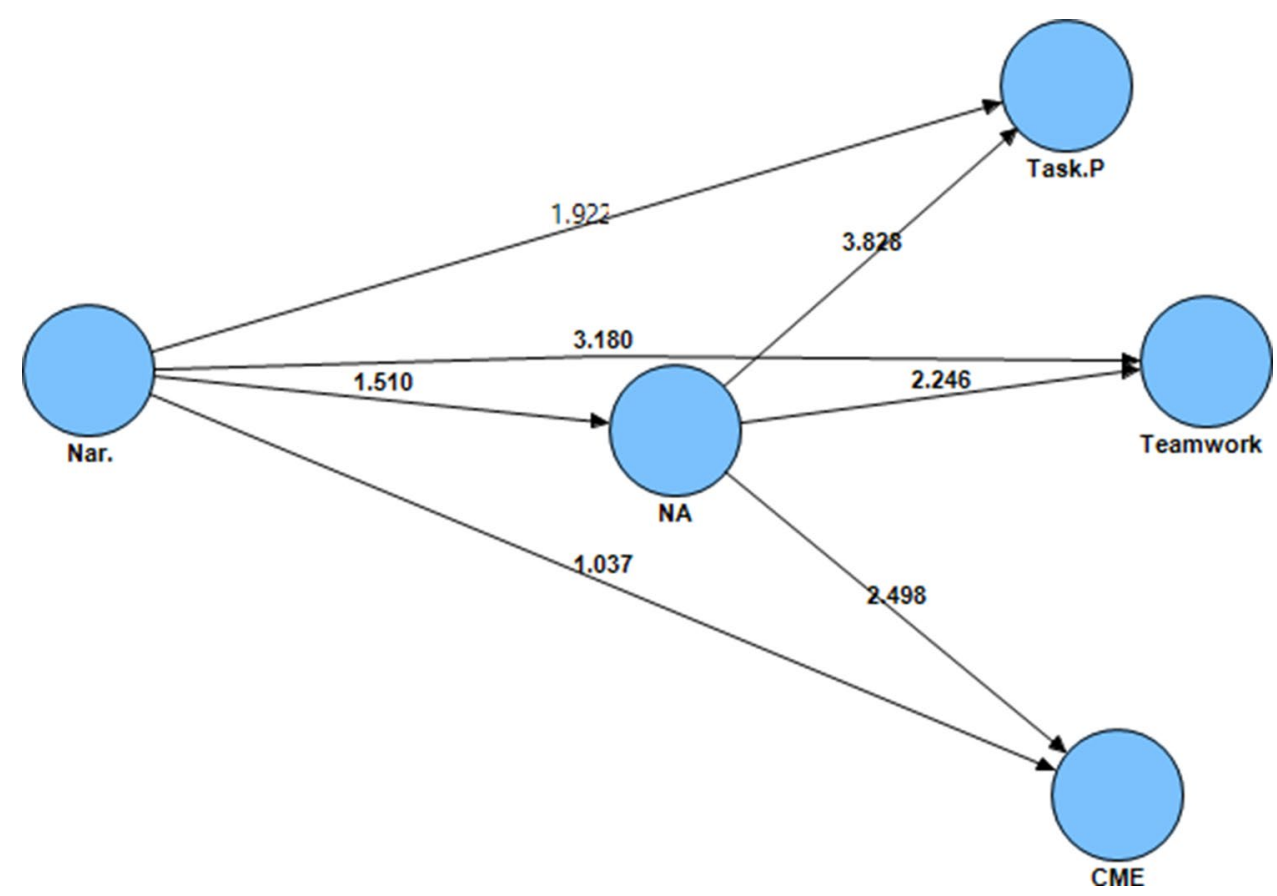

dimension wise results are presented in Figs. 1,2 and 3 and comprehensive results in Table 2.

The mediation relationship of subjective wellbeing with narcissism and performance was computed using SmartPLS2 software. The path coefficient was transformed into $t$ statistic using bootstrapping (Hair et al. 2017). The dimension wise results are presented in Figs. 1, 2 and 3 and comprehensive results in Table 2.
The bootstrapping analysis was conducted and direct and indirect effects were analyzed. The Figs. 1, 2 and 3 also show the direct relationship between narcissism and performance (all three dimensions). It can be seen that narcissism is not directly effecting task performance and cognitive motivation effectiveness but significantly effecting teamwork $(\mathrm{t}=3.08,3.1,3.1 \mathrm{p}<0.001)$. For indirect effect, Preacher and Hayes $(2004,2008)$ interpretation was used and for mediation to be significant, the indirect must not straddle a ' 0 ' 
Fig. 3 Satisfaction with life (SWL) as mediator of narcissism (Nar.) and performance (task performance, teamwork and cognitive motivational effectiveness, CME)

Table 2 Hypothesis Testing on mediation through wellbeing dimensions on narcissism and performance

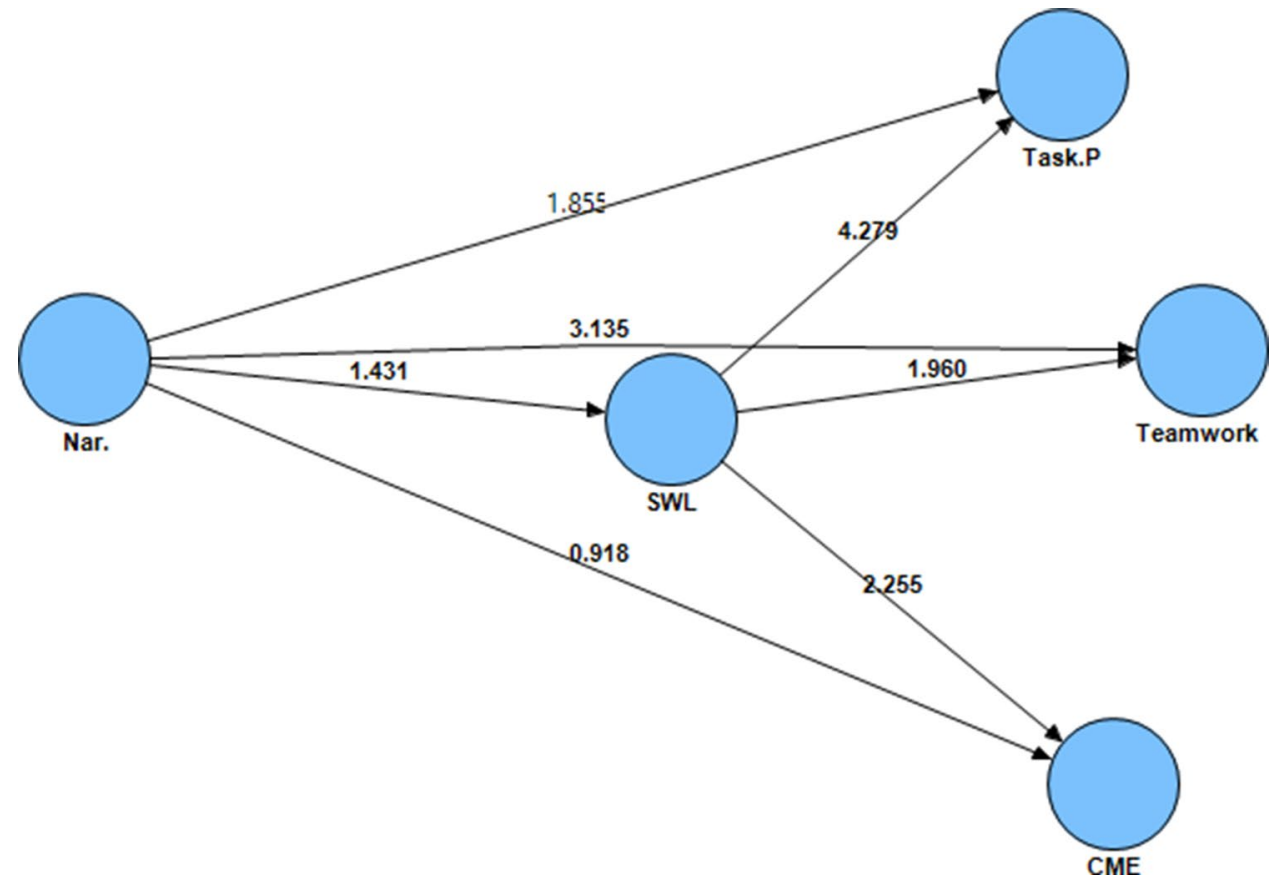

Relationship

Coefficient
(standard beta)

Percentile Bootstrap,5\%, LL- 95\%, UL CI

\begin{tabular}{lrlrl}
\hline Narcissism $\rightarrow \mathrm{PA} \rightarrow$ task performance & -0.08 & 0.93 & $-0.261,0.103$ & 0.18 \\
Narcissism $\rightarrow \mathrm{PA} \rightarrow$ teamwork & -0.10 & 1.01 & $-0.311,0.100$ & 0.19 \\
Narcissism $\rightarrow \mathrm{PA} \rightarrow \mathrm{CME}$ & -0.02 & 0.19 & $-0.191,0.221$ & 0.03 \\
Narcissism $\rightarrow \mathrm{NA} \rightarrow$ task performance & 0.35 & $3.82^{* * *}$ & $0.191,0.537$ & 0.64 \\
Narcissism $\rightarrow \mathrm{NA} \rightarrow$ team work & 0.22 & $2.24^{*}$ & $0.176,0.312$ & 0.44 \\
Narcissism $\rightarrow \mathrm{NA} \rightarrow \mathrm{CME}$ & 0.27 & $2.49^{*}$ & $0.057,0.493$ & 0.75 \\
Narcissism $\rightarrow \mathrm{SWL} \rightarrow$ task performance & 0.34 & $4.27^{* * *}$ & $0.019,0.507$ & 0.79 \\
Narcissism $\rightarrow \mathrm{SWL} \rightarrow$ team work & 0.18 & $1.96^{*}$ & $0.032,0.378$ & 0.59 \\
Narcissism $\rightarrow \mathrm{SWL} \rightarrow \mathrm{CME}$ & 0.25 & $2.25^{* *}$ & $0.055,0.464$ & 0.73 \\
\hline
\end{tabular}

$P A$ positive affect, $N A$ negative affect, $S W L$ satisfaction with life, $C M E$ cognitive motivational effectiveness, $U L$ upper level, $L L$ lower level, VAF variance accounted for values

${ }^{*} p<0.05, * * p<0.01, * * * p<0.001$,
(Zero). Further, Variance Accounted For values (VAF) were computed so as understand the strength of mediation. As a rule of thumb, if VAF is less than 20 percent, than there is zero mediation, if VAF is larger than 20 percent and less than 80 percent is characterized as partial mediation and a VAF above 80 percent indicates a full mediation (Hair et al. 2017).

The bootstrapping analysis shows that indirect effects of positive affect to task performance, teamwork and cognitive motivational effectiveness are insignificant $(\beta=-0.08$, $\mathrm{t}=0.93 ; \beta=-0.10, \mathrm{t}=1.01$ and $\beta=-0.02, \mathrm{t}=0.19)$. The indirect paths through positive affect were found to be insignificant and VAF is below 0.20 , thus, disapproved hypothesis 2.
The result of next mediation bootstrapping analysis, shows that negative affect mediated all three dimensions of performance significantly (task performance $\beta=0.35$, $\mathrm{t}=3.82$; teamwork, $\beta=0.22, \mathrm{t}=2.24$; cognitive motivational effectiveness $\beta=0.27, t=2.49$ ). The results also imply that negative affect partially mediates the relationship between narcissism and performance as VAF values are less than 0.80 but more than 0.20 . Hence, supports hypothesis 3 .

The bootstrapping results confirm the mediating relationship of satisfaction with life between narcissism and performance (task performance $\beta=0.34, t=4.27$; teamwork, $\beta=0.18, t=1.96$; cognitive motivational effectiveness $\beta=0.25, t=2.25$ ). The results also imply that satisfaction with life affect partially mediates the relationship 
between narcissism and performance as VAF values are less than 0.80 but more than 0.20 . Hence, accepts hypothesis 4.

Thus, from the above results, it can be said that there is full support for hypothesis 3 and 4, partial support for hypothesis 1 and hypothesis 2 is rejected. Further, positive affect does not mediate the relationship between narcissism and performance whereas negative affect and satisfaction with life partially mediate the relationship between narcissism and performance (task performance, teamwork and cognitive motivational effectiveness). The results are discussed below.

\section{Discussion}

The results of the correlation table (1) indicate that grandiose narcissism is negatively related to all dimensions of performance. There is contrary evidence that grandiose narcissism and performance are positively related to each other (Galvin et al. 2010; Chatterjee and Hambrick 2007). However, narcissists also have incomprehensible goals, weak presence of mind and are intimidating because of which they poorly perform (Reijntjes et al. 2016; Chatterjee \& Hambrick 2011). These moderating/mediating factors get overlooked in direct one to one relationship (Field 2013). Similarly, the relationship between narcissism and emotional state is more organic than deliberate and it may have a detrimental effect on other organizational outcomes. Narcissism is associated with emotion regulation difficulties (Jauk et al. 2016) and is highly correlated with negative affect (Jauk et al. 2017) and has less satisfaction with life (Kopelman and Mullins 2012) which is also evident in the correlation results above. Further, negative affect has cognitive flexibility and increased or decreased motivation or attention is said to be context or task-based (Gable and Harmon-Jones 2010). There are ample characterizations of narcissism as an impulsive trait having fluctuating emotions and wellbeing (Rose 2002; Hickman et al. 1996; Czarna et al. 2016). Narcissism and emotional state works in tandem which may have varied impact on performance. There are studies which have also established direct relationships of narcissism with productive as well as nonproductive performance (Galvin et al. 2010; Rosenthal and Pittinksky 2006; Imran and Shahnawaz 2020; Sakkar Sudha and Shahnawaz 2020). Hence, it's evident that simple correlation results could be misleading. Thus, it can be hypothesized that narcissism trait will lead to positive as well as negative emotions and satisfaction (i.e., SWB) which would ultimately result in performance.

The mediation models were examined (see Figs. 1, 2 and 3 and Table 2) and results suggest that positive affect did not mediate the relationship of narcissism with performance. Narcissistic managers are generally authoritative (Nevicka et al. 2011; Imran and Shahnawaz 2020; Sakkar Sudha and Shahnawaz 2020) therefore, the performance of narcissistic managers are short lived. The idea of power and fantasy dominates grandiose narcissism which sometimes makes goal setting difficult for them (Rosenthal 2010) which may become incomprehensible and may lead to compromised teamwork. Positive affect has not mediated the relationship between narcissism and CME as well, meaning narcissists are not able to balance their emotions with motivations or attentions due to which their performance is often short-lived (Rosenthal and Pittinksky 2006). These surmise some of the key reasons for positive affect not mediating the relationship between narcissism and performance.

The results also revealed that negative affect mediated the relationships between narcissism and performance. Grandiose narcissism and negative affect may not be directly related to each other but the self-processing of narcissism is accompanied by emotional conflicts as well (Cascio et al. 2015). A scientific report published by Jauk et al. (2017) conducted an fMRI on narcissistic men (Scored high on NPI inventory) and scientifically proved that negative affect is like a subliminal characteristic even in the case of grandiose narcissism, it is present but might not be noticeable in self-reports or other personality assessments. It would be interesting to report that narcissism and negative affect were both inversely correlated with depression, anxiety or other maladaptive aspects (Watson and Biderman 1993). Negative affect may also construe over-engagement or tiredness which have proved a significant relationship with performance (Niessen et al. 2012; Bakker and Demerouti 2007). The emotional, cognitive and motivational self-regulation if compatible with the work situation might prove productive even if the negative affect is high (Gable and Harmon-Jones 2010). Teamwork also requires communication and coordination among all the team members for the goals to be achieved (Paris et al. 2000) which narcissistic are considered to be good at. Task performance and cognitive effectiveness are self-implicit and with exceptionally good emotion regulation narcissists may easily become the favorites in their team. These particularize reasons for negative affect mediating the relationship of narcissism with performance as we have found in the present study.

Satisfaction with life (Cognitive aspect of wellbeing) has significantly mediated the relationship between grandiose narcissism and all the dimensions of performance. Grandiose narcissism and life satisfaction are positively related to each other (Rohmann et al. 2019; Sedikides et al. 2004). The primary reasons for higher life satisfaction can be attributed to streaming positive emotions, higher self-esteem, self-enhancement disposition of narcissistic 
individuals (Hill and Roberts 2012; Diener \& Diener 2009). Narcissistic tend to exhibit desirable behaviors (Foster and Trimm 2008), often fantasize (coping mechanism) to present themselves as happy in various domains of life (Raskin and Novacek 1991) and may project themselves as goal achievers (Watts et al. 2013; Campbell et al. 2004). On the other hand, narcissists are excellent communicators, power influencers and have an enchanting demeanor where they can captivate people and involve them in their vision (Reijman 2017; Montalvo et al. 2015; Maccoby 2004). It is hence, their gratification with life and charming persona which enables narcissistic to manifest the desired behavior to get tasks done or involve the team.

\section{Conclusion, implications and limitations}

Since narcissism is a unique trait which has its roots in personality and emotion theories, it is strongly connected to self-regulation factors such as emotions and wellbeing. The study hence is a first of its kind to analyze the mediating role of subjective wellbeing on grandiose narcissism and organizational performance. The holistic approach to measure performance by considering cognitive adaptability, team and task-related aspect is the second highlight of this study. The correlation results showed that grandiose narcissism was negatively related to all dimensions of performance. Correlation results also showed that grandiose narcissism is positively and significantly related to negative affect but negatively to positive affect and life satisfaction. Further, indirect pathways revealed that negative affect and life satisfaction mediated the relationship between grandiose narcissism and performance. The results may help to clarify the impact of self-regulative emotional state and life satisfaction among grandiose narcissistic individuals. The task or team outcome would depend on contingency in which positive and negative affect is used to cognize and use it defensibly in demanding times. The results are beneficial as it helps in resolving the confusion between narcissism and performance literature by presenting clearer pathways of grandiose narcissism (through self-regulated emotions and subjective wellbeing). Thus negative affect would not always hinder performance, it depends under which contingencies and challenges narcissist leaders have chosen to react that way. Organizations must invest in a futuristic vision of narcissistic leaders as they may prove productive and focus on over-all wellbeing so that they can channelize their vims through their remarkable performances. The present research has added significantly to the existing literature, but there were notable limitations as well. Grandiose narcissism is still debated to be distinctive from normal narcissistic personality trait but no specified tool with clearer dimensions has been developed or used. Moreover, only grandiose narcissism is examined in the current research, and therefore, it should not be generalized to all forms of narcissism. We have argued about emotional self-regulatory processes and subjective wellbeing which would impact the performance; however, we did not explore the organizational and other personality/situational variables which would have moderated these relationships. Another limitation of the current research is the self-reported nature of data and we are fully aware of the problems (social desirability and common method biases etc.) associated with it. It is hoped that future researchers will take up some of these concerns and develop a more robust model of narcissism so that its relationship with performance is more clearly spelled out.

\section{Compliance with ethical standards}

Conflict of interest The authors declare that they have no conflict of interest.

Informed consent The informed consent was obtained at the time of original data collection and the participants' details have been properly anonymized.

Open Access Dieser Artikel wird unter der Creative Commons Namensnennung 4.0 International Lizenz veröffentlicht, welche die Nutzung, Vervielfältigung, Bearbeitung, Verbreitung und Wiedergabe in jeglichem Medium und Format erlaubt, sofern Sie den/die ursprünglichen Autor(en) und die Quelle ordnungsgemäß nennen, einen Link zur Creative Commons Lizenz beifügen und angeben, ob Änderungen vorgenommen wurden. Die in diesem Artikel enthaltenen Bilder und sonstiges Drittmaterial unterliegen ebenfalls der genannten Creative Commons Lizenz, sofern sich aus der Abbildungslegende nichts anderes ergibt. Sofern das betreffende Material nicht unter der genannten Creative Commons Lizenz steht und die betreffende Handlung nicht nach gesetzlichen Vorschriften erlaubt ist, ist für die oben aufgeführten Weiterverwendungen des Materials die Einwilligung des jeweiligen Rechteinhabers einzuholen. Weitere Details zur Lizenz entnehmen Sie bitte der Lizenzinformation auf http://creativecommons .org/licenses/by/4.0/deed.de.

\section{References}

American Psychiatric Association (2000). Diagnostic and Statistical Manual of Mental Disorders, (DSM-IV-TR-4th ed, Text Revision). American Psychiatric Publishing, Washington, DC. https://doi. org/10.1176/appi.books.9780890423349

Ames D, Kammrath L (2004) Mind-reading and metacognition: narcissism, not actual competence, predicts self-estimated ability. J Nonverbal Behav 28(3):187-209. https://doi.org/10.1023/ b:jonb.0000039649.20015.0e

Ames DR, Rose P, Anderson CP (2006) The NPI-16 as a short measure of narcissism. J Res Pers 40:440-450. https://doi.org/10.1016/j. jrp.2005.03.002

Aradhye C, Vonk J (2014) Theory of mind in vulnerable and grandiose narcissism. In: Besser A (ed) Psychology of emotions, motivations 
and actions. Handbook of the psychology of narcissism: diverse perspectives. Nova Science Publishers, New York, pp 347-361

Bakker AB, Demerouti E (2007) The job demands-resources model: state of the art. J Manag Psychol 22(3):309-328. https://doi. org/10.1108/02683940710733115

Bashaer A, Singh S, Sherine F (2016) Determinants of organizational performance: a proposed framework. Int J Prod Perform Manag 65(6):844-859

Braun S (2017) Leader narcissism and outcomes in organizations: a review at multiple levels of analysis and implications for future research. Front Psychol 8:773. https://doi.org/10.3389/fpsyg 2017.00773

Bryson A, Forth J, Stokes L (2017) Does employees' subjective wellbeing affect workplace performance? Human Relat 70(8):10171037. https://doi.org/10.1177/0018726717693073

Campbell WK, Campbell SM (2009) On the self-regulatory dynamics created by the peculiar costs and benefits of narcissism: a contextual reinforcement model and examination of leadership. Self Identity 8:214-232. https://doi.org/10.1080/15298860802505129

Campbell JP, Gasser MB, Oswald FL (1996) The substantive nature of job performance variability. In: Murphy KR (ed) Individual differences and behavior in organizations. Jossey-Bass, San Francisco, pp 258-299

Campbell WK, Goodie AS, Foster JD (2004) Narcissism, confidence, and risk attitude. J Behav Dec Mak 17:297-311. https://doi. org/10.1002/bdm. 475

Campbell WK, Reeder GD, Sedikides C, Elliot AJ (2000) Narcissism and Comparative Self-Enhancement Strategies. J Res Pers 34(3):329-347. https://doi.org/10.1006/jrpe.2000.2282

Cascio CN, Konrath SH, Falk EB (2015) Narcissists' social pain seen only in the brain. Soc Cogn Affect Neurosci 10:335-341. https:// doi.org/10.1093/scan/nsu072

Chatterjee A, Hambrick DC (2007) It's all about me: narcissistic CEO'S and their effects on company strategy and performance. Adm Sci Q 52:351-386. https://doi.org/10.2189/asqu.52.3.351

Chatterjee A, Hambrick DC (2011) Executive personality, capability cues, and risk taking how narcissistic ceos react to their successes and stumbles. Adm Sci Q 56(2):202-237. https://doi. org/10.1177/0001839211427534

Chen S, Friesdorf R, Jordan CH (2019) State and trait narcissism predict everyday helping. Self Identity. https://doi.org/10.1080/15298 868.2019.1598892 (Advance online publication)

Cheng JT, Tracy JL, Miller GE (2013) Are narcissists hardy or vulnerable? The role of narcissism in the production of stress-related biomarkers in response to emotional distress. Emotion 13:10041011. https://doi.org/10.1037/a0034410

Czarna AZ, Leifeld P, Śmieja M, Dufner M, Salovey P (2016) Do narcissism and emotional intelligence win us friends? Modeling dynamics of peer popularity using inferential network analysis. Pers Soc Psychol Bull 42:1588-1599. https://doi. org/10.1177/0146167216666265

Czarna, A. and Nevicka, B. (Eds.). (2019). Narcissism and leadership. Encyclopedia of personality and individual differences. Springer, Cham. https://doi.org/10.1007/978-3-319-28099-8_2334-1

Deci EL, Ryan RM (2008) Self-determination theory: a macrotheory of human motivation, development, and health. Can Psychol 49(3):182-185. https://doi.org/10.1037/a0012801

Diener E (2000) Subjective well-being: the science of happiness and a proposal for a national index. Am Psychol 55:34-43. https://doi. org/10.1037/0003-066x.55.1.34

Diener E, Emmons RA, Larsen RJ, Griffin S (1985) The satisfaction with life scale. J Pers Assess 49:71-75. https://doi.org/10.1207/ s15327752jpa4901_13

Diener E, Diener M (2009) Cross-cultural correlates of life satisfaction and self- esteem. In Culture and Well-Being. Springer, Netherlands, pp 71-91. https://doi.org/10.1007/978-90-481-2352-0_4
Field A (ed) (2013) Discovering statistics using IBM SPSS statistics: and sex and drugs and rock ' $n$ ' roll, 4th edn. Sage, London

Foster JD, Trimm RF (2008) On being eager and uninhibited: narcissism and approach-avoidance motivation. Pers Soc Psychol Bull 34:1004-1017. https://doi.org/10.1177/0146167208316688

Foster JD, Twenge JM (2011) Narcissism and relationships: From light to dark. In Cupach WR, Spitzberg BH (eds) The dark side of close relationships II. Routledge/Taylor \& Francis Group, New York, pp 381-407 https://doi.org/10.4135/9781412958479.n123

Furtner MR, Maran T, Rauthmann JF (2017) Dark leadership: the role of leaders' dark triad personality traits. In: Clark M, Gruber C (eds) Leader development deconstructed. Annals of theoretical psychology, (vol 15). Springer, Cham, pp 75-99. https://doi. org/10.1007/978-3-319-64740-1_4

Gable P, Harmon-Jones E (2010) The blues broaden, but the nasty narrows: attentional consequences of negative affects low and high in motivational intensity. Psychol Sci 21:211-215. https:// doi.org/10.1177/0956797609359622

Galvin B, Waldman D, Balthazard P (2010) Visionary communication qualities as mediators of the relationship between narcissism and attributions of leader charisma. Pers Psychol 63(3):509-537. https ://doi.org/10.1111/j.1744-6570.2010.01179.x

Gentile B, Miller JD, Hoffman BJ, Reidy DE, Zeichner A, Campbell WK (2013) A test of two brief measures of grandiose narcissism: the narcissistic personality inventory-13 and the narcissistic personality inventory-16. Psychol Assess 25(4):1120-1136. https://doi.org/10.1037/a0033192

Gornik-Durose ME (2020) Materialism and well-being revisited: the impact of personality. J Happiness Stud 21:305-326. https://doi. org/10.1007/s10902-019-00089-8

Grapsas S, Brummelman E, Back MD, Denissen JJA (2020) The "why" and "how" of narcissism: a process model of narcissistic status pursuit. Perspect Psychol Sci 15(1):50-172. https://doi. org/10.31234/osf.io/sy9fn

Greene Shortridge TM (2008) Proximal and longitudinal outcome of person-environment fit: a positive psychological approach. UMI Microform, Proquest LLC, USA, p 3316391

Grijalva E, Harms PD, Newman DA, Gaddis BH, Fraley RC (2015) Narcissism and leadership: a meta-analytic review of linear and nonlinear relationships. Pers Psychol 68:1-47. https://doi. org/10.1111/peps.12072

Hair JF, Hult TM, Ringle CM, Sarstedt M (2017) A primer on partial least square structural equation modeling (PLS-SEM). Sage Publications, New York

Harris PR, Harris KG (1996) Managing effectively through teams. Team Perform Manag 2(3):23-36. https://doi. org/10.1108/13527599610126247

Harrison DA, Newman DA, Roth PL (2006) How important are job attitudes? Meta-analytic comparisons of integrative behavioral outcomes and time sequences. Acad Manag J 49:305-325. https ://doi.org/10.5465/amj.2006.20786077

Hickman S, Watson P, Morris R (1996) Optimism, pessimism, and the complexity of narcissism. Personal Individ Differ 20:521525. https://doi.org/10.1016/0191-8869(95)00223-5

Hill P, Roberts B (2012) Narcissism, well-being, and observer-rated personality across the lifespan. Soc Psychol Personal Sci 3:216223. https://doi.org/10.1177/1948550611415867

Imran M, Shahnawaz G (2020) PsyCap and Performance: Wellbeing at Work as a Mediator. Asia-Pacific J Manag Res Innov 16(2):93102. https://doi.org/10.1177/2319510X20915999

Isen AM, Baron RA (1991) Positive affect as a factor in organizational behavior. In: Cummings LL, Starr BM (eds) Research in organizational behavior, vol 13. JAI Press, Greenwich, pp 1-53

Jauk E, Freudenthaler HH, Neubauer AC (2016) The dark triad and trait versus ability emotional intelligence. Emotional darkness 
differs between women and men. J Individ Differ 37:112-118. https://doi.org/10.1027/1614-0001/a000195

Jauk E, Benedek M, Koschutnig K, Kedia G, Neubauer AC (2017) Retrieved from: https://www.nature.com/articles/s41598-01703935-y.pdf?proof=t on 20 April, 2020

Judge TA, Zapata CP (2015) The person-situation debate revisited: Effect of situation strength and trait activation on the validity of the big five personality traits in predicting job performance. Acad Manag J 58(4):1149-1170. https://doi.org/10.5465/ amj.2010.0837

Kanfer R (1992) Work motivation: new directions in theory and research. In: Cooper CL, Robertson IT (eds) International review of industrial and organizational psychology, vol 7. Wiley, Chichester, pp 1-53

Kopelman R, Mullins L (2012) Is narcissism inversely related to satisfaction? An examination of data from two U.S. Samples. J Psychol Interdiscip Applied 126:121-130. https://doi.org/10.1080/00223 980.1992.10543346

Krizan Z, Herlache AD (2018) The narcissism spectrum model: a synthetic view of narcissistic personality. Personal Soc Psychol Rev 22:3-31. https://doi.org/10.1177/1088868316685018

Krusemark EA, Campbell WK, Crowe ML, Miller JD (2018) Comparing self-report measures of grandiose narcissism, vulnerable narcissism, and narcissistic personality disorder in a male offender sample. Psychol Assess 30(7):984-990. https://doi.org/10.31234 /osf.io/g9jtx

Lobbestael J, de Bruin A, Kok E, Voncken M (2016) Through rosecoloured glasses: an empirical test of narcissistic overestimation. Personal Mental Health 10(4):305-316. https://doi.org/10.1002/ pmh.1347

Lubit R (2002) The long term organizational impact of destructively narcissistic managers. Acad Manag Exec 16(1):127-138. https:// doi.org/10.5465/ame.2002.6640218

Maccoby M (2004) Narcissistic leaders: the incredible pros, the inevitable cons. Harvard Bus Rev 82:92-101

Malkin ML, Zeigler-Hill V, Barry CT, Southard AC (2012) The view from the looking glass: how are narcissistic individuals perceived by others? J Pers 81:1-15. https://doi.org/10.111 1/j.1467-6494.2013.00780.x

McCrae RR (2000) Emotional intelligence from the perspective of the Five-Factor Model of Personality. In: Bar-On R, Parker JDA (eds) The handbook of emotional intelligence. Jossey-Bass, San Francisco, pp 263-276

Meier LL, Semmer NK (2013) Lack of reciprocity, narcissism, anger, and instigated workplace incivility: a moderated mediation model. Eur J Work Org Psychol 22(4):461-475. https://doi. org/10.1080/1359432X.2012.654605

Miller JD, Gentile B, Wilson L, Campbell WK (2013) Grandiose and vulnerable narcissism and the DSM-5 pathological personality trait model. J Pers Assess 95:284-290. https://doi. org/10.1080/00223891.2012.685907

Miller JD, Lynam DR, Hyatt CS, Campbell WK (2017) Controversies in narcissism. Ann Rev Clin Psychol 13(1):291-315. https://doi. org/10.1146/annurev-clinpsy-032816-045244

Miller JD, McCain J, Lynam DR, Few LR, Gentile B (2014) A comparison of the criterion validity of popular measures of narcissism and narcissistic personality disorder via the use of expert ratings. Psychol Assess 26:958-969. https://doi.org/10.1037/a0036613

Miller JD, Price J, Campbell WK (2012) Is the Narcissistic Personality Inventory still relevant? A test of independent grandiosity and entitlement scales in the assessment of narcissism. Assessment 19(1):8-13. https://doi.org/10.1177/1073191111429390

Miller JD, Widiger TA, Campbell WK (2014) Vulnerable narcissism: Commentary for the special series "Narcissistic personality disorder-new perspectives on diagnosis and treatment. Personal
Disord Theory Res Treat 5:450-451. https://doi.org/10.1037/ per0000083

Montalvo D (2015) Narcissism actually produces results: the rise of the world changers. Retrieved from: https://www.cnbc. com/2015/06/04/facebook-tesla-ceos-examples-of-productive -narcissism.html on 8 April 2018

Morf CC, Rhodewalt F (2001) Unraveling the paradoxes of narcissism: a dynamic self-regulatory processing model. Psychol Inq 12:177-196. https://doi.org/10.1207/s15327965pli1204_1

Motowidlo SJ, Schmit MJ (1999) Performance assessment in unique jobs. In: Ilgen DR, Pulakos ED (eds.), The changing nature of job performance: Implications for staffing, motivation, and development. Jossey-Bass, San Francisco, pp 56-86. https://doi. org/10.1002/hrdq.9

Nesse RM (1990) Evolutionary explanations of emotions. Human Nature 1:261-289

Nevicka B, Ten Velden FS, De Hoogh AHB, Van Vianen AEM (2011) Reality at odds with perceptions: narcissistic leaders and group performance. Psychol Sci 22(10):1259-1264. https://doi. org/10.1177/0956797611417259

Niessen C, Sonnentag S, Sach F (2012) Thriving at work- A diary study. Journal of Organizational Behaviors 33:468-487. https:// doi.org/10.1002/job.763

Oswald AJ, Proto E, Sgroi D (2015) Happiness and productivity. J Labor Econ 33(4):789-822. https://doi.org/10.1086/681096

Owens BP, Wallace AS, Waldman DA (2015) Leader narcissism and follower outcomes: the counterbalancing effect of leader humility. J Appl Psychol 100(4):1203-1213. https://doi.org/10.1037/ a0038698

Paris CR, Salas E, Cannon-Bowers JA (2000) Teamwork in multi-person systems: a review and analysis. Ergonomics 43(8):1052-1075. https://doi.org/10.1080/00140130050084879

Pavot W, Diener E (2003) Well-being (including life satisfaction). In: Fernandez-Ballesteros R (ed) Encyclopedia of psychological assessment, (vol 2). Sage, London, pp 1097-1101. https://doi. org/10.4135/9780857025753.n232

Pilch I (2020) As cold as a fish? Relationships between the Dark Triad personality traits and affective experience during the day: a day reconstruction study. PLoS ONE 15(2):e0229625. https://doi. org/10.1371/journal.pone.0229625

Pincus AL, Lukowitsky MR (2010) Pathological narcissism and narcissistic personality disorder. Ann Rev Clin Psychol 6:421-446. https ://doi.org/10.1146/annurev.clinpsy.121208.131215

Preacher KJ, Hayes AF (2004) SPSS and SAS procedures for estimating indirect effects in simple mediation models. Behav Res Methods Instrum Comput 36(4):717-731

Preacher KJ, Hayes AF (2008) Asymptotic and resampling strategies for assessing and comparing indirect effects in multiple mediator models. Behav Res Methods 40(3):879-891

Raskin R, Novacek J (1991) Narcissism and the use of fantasy. J Clin Psychol 47(4):490-499. https://doi.org/10.1002/1097-4679(19910 7) $47: 4 \% 3 c 490::$ aid-jclp2270470404\%3e3.0.co;2-j

Raskin R, Terry H (1988) A principal-components analysis of the narcissistic personality inventory and further evidence of its construct validity. J Pers Soc Psychol 54:890-902. https://doi. org/10.1037/0022-3514.54.5.890

Reijman M (2017) Why little bit of narcissism can be a good thing. Retrieved from: https://www.thestar.com.my/business/businessnews/2017/08/12/why-a-little-bit-of-narcissism-can-be-a-goodthing/\#3Er7d2bck1VCsjpa on 8 April 2018

Reijntjes A, Vermande M, Thomaes S, Goossens F, Olthof T, Aleva L, Vander Meulen M (2016) Narcissism, bullying, and social dominance in youth: a longitudinal analysis. J Abnorm Child Psychol 44:63-74. https://doi.org/10.1007/s10802-015-9974-1

Roche MJ, Pincus AL, Lukowitsky MR, Ménard KS, Conroy DE (2013) An integrative approach to the assessment of narcissism. 
J Pers Assess 95:237-248. https://doi.org/10.1080/00223 891.2013.770400

Rohmann E, Hanke S, Bierhoff H-W (2019) Grandiose and vulnerable narcissism in relation to life satisfaction, self-esteem, and self-construal. J Individ Differ 40(4):194-203. https://doi. org/10.1027/1614-0001/a000292

Rose P (2002) The happy and unhappy faces of narcissism. Personal Individ Differ 33:379-391. https://doi.org/10.1016/s0191 -8869(01)00162-3

Rosenthal SA, Pittinsky TL (2006) Narcissistic leadership. Leadersh Q 17(6):617-633. https://doi.org/10.1016/j.leaqua.2006.10.005

Rosenthal S (2010) Narcissism and leadership: a review and research agenda, Centre for Public Leadership, Harvard University. Retrieved from https://dspace.mit.edu/handle/1721.1/55948 on 10, August, 2019

Sakkar Sudha K, Shahnawaz MG (2020) Narcissism personality trait and performance: task oriented leadership and authoritarian styles as mediators. Leadersh Org Dev J 41(2):280-293. https://doi. org/10.1108/LODJ-09-2019-0399

Sandage S, Jankowski P, Bissonette C, Paine D (2016) Vulnerable narcissism, forgiveness, humility, and depression: mediator effects for differentiation of self. Psychoanal Psychol 34(3):1-11. https://doi. org/10.1037/pap0000042

Scarnati JT (2001) On becoming a team player. Team Perform Manag 7(1/2):5-10. https://doi.org/10.1108/13527590110389501

Sedikides C, Campbell WK (2017) Narcissistic force meets systemic resistance: the energy clash model. Perspect Psychol Sci 12:400 421. https://doi.org/10.1177/1745691617692105

Sedikides C, Rudich EA, Gregg AP, Kumashiro M, Rusbult C (2004) Are normal narcissists psychologically healthy? Selfesteem matters. J Pers Soc Psychol 87:400-416. https://doi. org/10.1037/0022-3514.87.3.400
Tett RP, Burnett DD (2003) A personality trait-based interactionist model of job performance. J Appl Psychol 88(3):500-517. https ://doi.org/10.1037/0021-9010.88.3.500

Uji M, Yukihiro T, Adachi K (2014) Narcissistic grandiose self: its defensive function against depressive mood and the damage it causes in the context of negative interpersonal life events. In: Besser A (ed) Psychology of emotions, motivations and actions. Handbook of the psychology of narcissism: diverse perspectives. Nova Science Publishers, New York, pp 215-226

Wallace HM, Baumister RF (2002) The performance of narcissists rises and falls with perceived opportunity of glory. J Pers Soc Psychol 82:819-834. https://doi.org/10.1037/0022-3514.82.5.819

Watson PJ, Biderman MD (1993) Narcissistic personality inventory factors, splitting, and self-consciousness. J Pers Assess 61:41-57. https://doi.org/10.1207/s15327752jpa6101_4

Watson D, Clark LA, Tellegen A (1988) Development and validation of brief measures of positive and negative affect: the PANAS scales. J Pers Soc Psychol 54(6):1063-1070. https://doi. org/10.1037/0022-3514.54.6.1063

Watts AL, Lilienfelds O, Smith SF, Miller JD, Campbell WK, Steven ID, Rubenzer J, Faschingbauer TJ (2013) The double-edged sword of grandiose narcissism: implications for successful and unsuccessful leadership among US Presidents. Psychol Sci 24(12):2379-2389. https://doi.org/10.1177/0956797613491970

Westen D (1990) The relations among narcissism, egocentrism, selfconcept, and self-esteem: experimental, clinical, and theoretical considerations. Psychoanal Contemp Thought 13:183-239

Wirtz N, Rigotti T (2020) When grandiose meets vulnerable: narcissism and well-being in the organizational context. Eur J Work Organ Psychol. https://doi.org/10.1080/1359432x.2020.1731474 